\title{
BMJ Open Nutritional status of children living within institution-based care: a retrospective analysis with funnel plots and control charts for programme monitoring
}

\author{
Emily DeLacey (10 , ${ }^{1,2,3}$ Evan Hilberg, ${ }^{2}$ Elizabeth Allen, ${ }^{1}$ Michael Quiring, ${ }^{2}$ \\ Cally J Tann, ${ }^{3,4,5}$ Nora Ellen Groce, ${ }^{6}{ }^{\text {James Vilus, }}{ }^{7}$ Ethan Bergman, ${ }^{8}$ \\ Merzel Demasu-Ay, ${ }^{9}$ Hang T Dam, ${ }^{2}$ Marko Kerac (1) ${ }^{1,3}$
}

To cite: DeLacey E, Hilberg E, Allen $\mathrm{E}$, et al. Nutritional status of children living within institution-based care: a retrospective analysis with funnel plots and control charts for programme monitoring. BMJ Open 2021;11:e050371. doi:10.1136/ bmjopen-2021-050371

- Prepublication history and additional supplemental material for this paper are available online. To view these files, please visit the journal online (http://dx.doi.org/10.1136/ bmjopen-2021-050371)

Received 21 February 2021 Accepted 06 December 2021

Check for updates

(C) Author(s) (or their employer(s)) 2021. Re-use permitted under CC BY-NC. No commercial re-use. See rights and permissions. Published by BMJ.

For numbered affiliations see end of article.

Correspondence to

Emily DeLacey;

emilyd@holtinternational.org

\section{ABSTRACT}

Objectives The aim of this study is to fill a key information gap on the nutrition-related epidemiology of orphaned and vulnerable children living within institutionbased care (IBC) across six countries.

Design A retrospective analysis with Shewhart control charts and funnel plots to explore intersite and over time variations in nutritional status.

Setting We conducted a retrospective analysis of records from Holt International's Child Nutrition Programme from 35 sites in six countries; Mongolia, India, Ethiopia, Vietnam, China and the Philippines.

Participants Deidentified health records from Holt International's online nutrition screening database included records from 2926 children, 0-18 years old. Data were collected from 2013 to 2020 and included demographic and health information.

Results At initial screening, 717 (28.7\%) children were anaemic, 788 (34.1\%) underweight, 1048 (37.3\%) stunted, $212(12.6 \%)$ wasted, 135 (12\%) overweight or obese and $339(31 \%)$ had small head circumference. Many had underlying conditions: low birth weight, 514 (57.5\%); prematurity, 294 (42.2\%) and disabilities, 739 (25.3\%). Children with disabilities had higher prevalence of malnutrition compared with counterparts without disabilities at baseline and 1-year screenings. There was marked intersite variation. Funnel plots highlight sites with malnutrition prevalence outside expected limits for this specific population taking into consideration natural variation at baseline and at 1 year. Control charts show changes in site mean z-scores over time in relation to site control limits.

Conclusions Malnutrition is prevalent among children living within IBC, notably different forms of undernutrition (stunting, underweight, wasting). Underlying risk factors are also common: prematurity, low birth weight and disability. Nutrition interventions should take into account the needs of this vulnerable population, especially for infants and those with disabilities. Using control charts to present data could be especially useful to programme managers as sites outside control limits could represent: problems to be investigated; good practices to be shared.

\section{Strengths and limitations of this study}

- The main strength of our study was the large sample size in both terms of individual children (including those with disabilities) and multiple centres across several countries.

- This study explored the utility of statistical process control charts and funnel plots to explore intersite and over time variations in malnutrition prevalence-these are established but under-used tools which might help managers monitor and ultimately improve programme outcomes.

- There were changes in the sample size over time

- The sites included in this sample may not be representative of all similar institutions in all of the countries.

\section{BACKGROUND}

UNICEF estimates there are 140 million orphans worldwide who have lost either one or both parents. ${ }^{1}$ Although most live with other family members, some live in institutionbased care (IBC) or residential care facilities. ${ }^{1}$ IBC is defined by the United Nations as residential care provided in any non-family-based group setting. ${ }^{2}$ The UN Convention on the Rights of the Child requires that children in IBC are provided with standards of living that will support their full development. There are 3.18 million to 9.42 million children ages 18 years and younger who live in IBC globally. ${ }^{3}$

Malnutrition continues to affect many countries worldwide with millions of children having inadequate access to nutritious food. ${ }^{4-6}$ Almost half of the deaths among children younger than 5 years old have undernutrition as an underlying factor. ${ }^{46}$ Malnutrition also predisposes children to long-term impairments such as 
diminished cognition, disability, non-communicable diseases and suboptimal performance at school and work. ${ }^{46}$ Dramatic worsening is anticipated as a result of the COVID-19 pandemic. $^{78}$

A recent systematic review exploring the nutritional status of children living in IBC found few studies directly documenting the problem. ${ }^{9}$ Where publications were available, 'data quality was often poor: as well as suboptimal reporting of anthropometry, few looked for or described disabilities, despite disability being common in this population and having a large potential impact on nutrition status. ${ }^{, 9}$ Disabilities in particular can be both a cause and a result of malnutrition. ${ }^{10}$ Interpreting data can be difficult due to limited information about children's lives prior to entering IBC. ${ }^{911-13}$ Pre-existing needs and adversities, including disabilities, low birth weight (LBW) or premature birth, or exposure to alcohol or drugs can impact nutritional status. ${ }^{911} 1314$

Once children enter into IBC, facilities might only be able to address their basic needs due to limited staffing, time and fiscal constraints. ${ }^{11}{ }^{15-17}$ Children's nutritional status could be impacted by inadequate dietary diversity; inappropriate types of food; poor feeding practices; inadequate attention or stimulation; suboptimal hygiene and sanitation. These can further exacerbate preadmission vulnerabilities, with the net result of: reduced nutrient utilisation, worsening malnutrition and a vicious cycle of increased vulnerability to illnesses and in turn further nutritional decline. ${ }^{9131618}$

In this paper, we seek to help contribute to the current small body of data on nutritional status of children in IBC by analysing data on 2926 children from 35 sites in six countries. Our objectives were to:

1. Describe children's nutritional status, focusing on core anthropometric measures of growth (underweight, wasting, stunting, overweight) and anaemia.

2. Explore intersite variations and potential factors underlying those, notably disability.

3. Explore any changes in nutritional status over time in IBC.

Cross-cutting these objectives, we also explored the utility of control charts and funnel plots to present key data in a way that may be used to track, monitor and evaluate nutritional status and programmes.

\section{METHODS}

We reported according to the Strengthening the Reporting of Observational Studies in Epidemiology statement (online supplemental file 1). ${ }^{19} \mathrm{~A}$ data use agreement was signed with Holt International for use of routinely collected data.

\section{Study design}

A retrospective analysis of nutrition screenings from a large multicountry nutrition programme.

\section{Setting/study size}

We used secondary data from Holt International's Child Nutrition Programme nutrition screening database. Holt International is a 65-year-old child welfare nonprofit, which provides services to children and families in numerous countries around the world. Holt's Child Nutrition Programme currently supports 35 IBC sites in six countries: Mongolia, India, China, Philippines, Ethiopia and Vietnam. Study size was determined by the number of children and nutrition screenings at each site. Figure 1 is a flow chart of inclusion criteria leading to the final sample size.

\section{Patient and public involvement}

This study analysed secondary deidentified routine programme audit data and did not involve patients or public in development of the research. However, we intend to disseminate this research to the public and all relevant stakeholders on open access publication.

\section{Participants}

Screenings from children 0-18 years old residing in IBC between January 2013 and June 2020 were included. These health/nutrition screenings were routinely performed at each site based on age and specific health indicators (eg, anaemia). They are carried out monthly on children up to 2 years old; quarterly on children $2-5$ years old and biannually thereafter. Each screening captures information on age, birth status, sex, disability status, time spent in care, episodes of illness, nutritional status as assessed by anthropometric measurements and anaemia as assessed by haemoglobin tests. Screenings and measurements were taken by trained staff using standardised equipment (Stadiometer (Seca $206 \mathrm{~cm}$ ), standing scale (Seca model $469)$, baby scale (Health-O-metre model $553 \mathrm{~kL}$ ), infant/ child length/height measurement board (Shorrboard), Hb201 +Haemoglobin System (Hemocue)).

\section{Variables}

Health indicators analysed included prevalence of stunting (height-for-age z-score, HAZ), wasting (weight-forheight z-score, WHZ and mid-upper arm circumferencefor-age z-score), underweight (weight-for-age z-score, WAZ), thinness/underweight (body mass index z-score, BMIZ), overweight (BMIZ), head circumference (head circumference-for-age z-score) and anaemia. Disabilities, as categorised by professionals in country, were grouped and tabulated by the primary disability listed. LBW and preterm birth were as noted in any preadmission health records.

\section{Statistical analysis}

Analysis was completed using Stata V.16. ${ }^{20}$ Children's baseline and last screening within each 6-month period were selected for analysis. Child health characteristics are described in tables 1 and 2 with $\mathrm{n}(\%)$ for categorical variables and means, SD, medians, and IQR for continuous variables. WHO diagnostic and data cleaning criteria for anthropometry and anaemia were used 


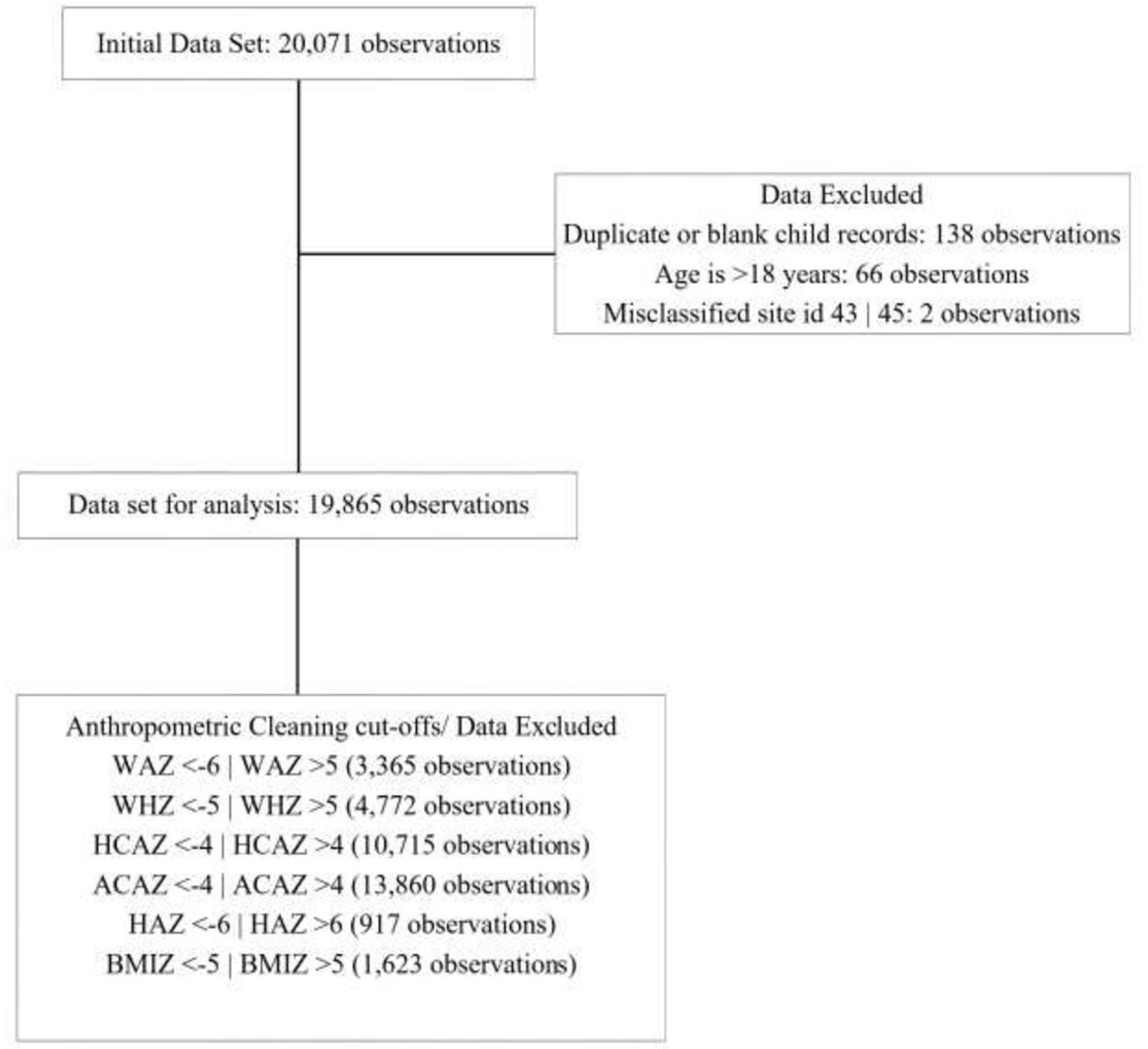

Figure 1 Data cleaning flow chart. ${ }^{19} \mathrm{BMIZ}$, body mass index z-score; HAZ, height-for-age z-score; HCAZ, head circumference-for-age z-score; WAZ, weight-for-age z-score; WHZ, weight-for-height z-score; ACAZ, mid-upper arm circumference-for-age z-score.

(haemoglobin levels for ages $0-5$ years: mild $10.0-10.9 \mathrm{~g} /$ $\mathrm{dL}$, moderate $7.0-9.9 \mathrm{~g} / \mathrm{dL}$, severe, $<7.0 \mathrm{~g} / \mathrm{dL}$; ages $5-11$ years: mild $11.0-11.4 \mathrm{~g} / \mathrm{dL}$, moderate $8.0-10.9 \mathrm{~g} / \mathrm{dL}$, severe, $<8.0 \mathrm{~g} / \mathrm{dL}$; ages $12-14$ years: mild $11.0-11.9 \mathrm{~g} / \mathrm{dL}$, moderate $8.0-10.9 \mathrm{~g} / \mathrm{dL}$, severe, $<8.0 \mathrm{~g} / \mathrm{dL}$; females aged $14+$ years: mild $11.0-11.9 \mathrm{~g} / \mathrm{dL}$, moderate $8.0-10.9 \mathrm{~g} /$ $\mathrm{dL}$, severe $<8.0 \mathrm{~g} / \mathrm{dL}$ and males aged 14+years: mild $11.0-12.9 \mathrm{~g} / \mathrm{dL}$, moderate $8.0-10.9 \mathrm{~g} / \mathrm{dL}$, severe $<8.0 \mathrm{~g} /$ $\mathrm{dL}){ }^{21-23}$ The time in programme is defined as the number of days from the registered admission date to exit and is censored at the date of the final observation for those remaining in care.

We used statistical process control (SPC) charts (Shewhart), which provide graphical representation of data and applies the statistical power of classical significance tests to analyse data chronologically while being easily interpreted and capable of identifying changes (figures 2 and 3, online supplemental annex 2-10).24 25 The central line and upper and lower control limits (UCL and LCL) define the expected amount of variability assuming expected variability due to sampling. Historically, control charts were used to determine if manufacturing processes were within expected variability; however recently they've been used in healthcare and development settings to distinguish random variations from statistically significant variations which may require further exploration/analysis. ${ }^{24}{ }^{25}$ Here, we use the control charts to explore changes over time in key anthropometric indicators and monitor the health of children in individual sites. We hypothesise that ongoing use of control charts will enable sites to take action accordingly. Different types of control charts exist for different types of data. For our anthropometric data we use X-bar charts, plotting the mean anthropometric z-scores at each time point for an individual site along with the site UCL and LCL. These control charts were created using site level aggregated mean z-scores for the nutritional status indicators at different time points based on the children's last screening in each 6-month period after baseline. The central line is the arithmetic mean and our UCL and LCL were calculated based on the mean and SE of the mean $( \pm 3)$ of aggregated data from the site at baseline.

A funnel plot plots the outcome of interest against a measure of study precision with more data resulting in more precision and creating the funnel shape. We used funnel plots for outcomes measured as proportions, plotting IBC sites against the absolute number of occurrences of our health outcomes of interest (eg, stunting) while taking into account the amount of available data from each site and plotting sites by size (smallest to largest) against the proportion of interest. The plot's mean and limits of 2 and 3 SEs identify sites for whom the prevalence/ 


\begin{tabular}{|c|c|c|c|}
\hline \multirow{2}{*}{\multicolumn{2}{|c|}{$\begin{array}{l}\text { Table } 1 \text { Description of population at baseline screening of } \\
\text { children living within IBC in six countries }\end{array}$}} & \multicolumn{2}{|l|}{ Table 1 Continued } \\
\hline & & Population at baseline & Total $(n=2926)$ \\
\hline Population at baseline & Total $(n=2926)$ & Total no exited & 1489 \\
\hline Age (\%) & & Active children & 1437 \\
\hline Exact date of birth unknown & 2639 (90.2) & Exit status reasons (\%) & $(n=1489)$ \\
\hline Estimated or known date of birth & $(n=2926)$ & Family reunification & $315(21)$ \\
\hline $0-6$ months & 746 (25.5) & Foster care placement & $29(2)$ \\
\hline $6-12$ months & $245(8.4)$ & Adoption (domestic) & $517(34.7)$ \\
\hline 12-24 months & $282(9.6)$ & Adoption(international) & $281(18.9)$ \\
\hline 24-59 months & 427 (14.6) & Aged out of care & $82(5.5)$ \\
\hline $5-18$ years & 1226 (41.9) & Transfer to a different centre & $103(6.9)$ \\
\hline Sex $(\%)$ & $(n=2926)$ & Death & $40(2.7)$ \\
\hline Female & $1435(49.0)$ & Other & $57(4.1)$ \\
\hline Disability (\%) & $(n=2926)$ & Programme closed & $65(4.4)$ \\
\hline
\end{tabular}

\begin{tabular}{ll} 
With one or more disabilities & $739(25.3)$ \\
\hline Common disabilities (\%) & $(\mathrm{n}=547)$ \\
\hline Autism spectrum disorder & $9(1.6)$ \\
Cerebral palsy & $100(18.2)$ \\
Cleft lip/cleft palate & $7(1.3)$
\end{tabular}

IBC, institution-based care.

outcome is unusually high or low. Together, these charts will allow us to assess individual site performance over time and enable appropriate targeted support.

$\begin{array}{lll}\text { Cognitive impairment } & 34(6.2) & \text { time and } \\ \text { Down syndrome } & 15(2.7) & \\ \text { Hearing loss/deafness } & 8(1.5) & \text { RESULTS } \\ \text { Heart disease/defect } & 35(6.4) & \text { We analyse }\end{array}$

\begin{tabular}{|ll}
\hline Heart disease/defect & $35(6.4)$ \\
\hline HIV/AIDS & $10(1.8)$ \\
\hline Hydrocephaly & $16(2.9)$ \\
\hline Microcephaly & $6(1.1)$ \\
\hline Vision impairment and blindness & $13(2.4)$ \\
\hline Speech/language delays & $3(0.6)$ \\
\hline Other & $291(53.2)$ \\
\hline Birth weight (\%) & $(\mathrm{n}=2926)$ \\
\hline Birth weight unknown & $2031(69.4)$ \\
\hline Where birth weight known & $(\mathrm{n}=895)$ \\
\hline Birth weight $>2.5 \mathrm{~kg}$ & $381(42.6)$ \\
\hline Low birth weight $<2.5 \mathrm{~kg}$ & $452(50.5)$ \\
\hline Very low birth weight $<1.5 \mathrm{~kg}$ & $55(6.2)$ \\
\hline Extremely low birth weight $<1.0 \mathrm{~kg}$ & $7(0.8)$ \\
\hline Birth status (\%) & $(\mathrm{n}=2926)$ \\
\hline Unknown birth status & $2229(76.2)$ \\
\hline Where birth status known & $(\mathrm{n}=697)$ \\
\hline Where known full term & $403(57.8)$ \\
\hline Where known premature & $294(42.2)$ \\
\hline Age at admission & $(\mathrm{n}=2926)$ \\
\hline Median age in months (IQR) & $10(0.4-71.8)$ \\
\hline Time since admission & $(\mathrm{n}=2926)$ \\
\hline Median time in months since admission & $20.7(8.9-49.2)$ \\
\hline (IQR) & $(\mathrm{n}=2926)$ \\
\hline Exit status & \\
\hline
\end{tabular}

We analysed data from 19865 nutrition records from 2926 children at 35 sites in six countries.

\section{Demographic characteristics}

Table 1 shows baseline characteristics of 2926 children living within IBC. The largest age groups were children 0-6 months $746(25.5 \%)$ and children older than 5 years of age 1226 (41.9\%); 1435 (49\%) were female; 739 (25.3\%) had one or more disabilities. A range of disabilities were reported. Cerebral palsy was the most common disability identified (100 (18.2\%)). However, 291 (53.2\%) children with disabilities had a disability which did not fall into established categories. Of those with a known birth weight, $514(57.5 \%)$ were born LBW. Of those children with a known gestational age, $294(42.2 \%)$ were born prematurely. Children came into IBC at a median age of 10 months (IQR: 0.4-71.8 months) and resided in IBC for a median time of 21.7 months (IQR: 9.7-50.9 months).

\section{Anthropometric characteristics}

Table 2 and online supplemental annex table 11 show details of anthropometric status. At baseline the mean weight-for-age $\mathrm{z}$-score for those $0-10$ years old was $-1.48 \pm 1.54$. The mean HAZ was $-1.74 \pm 1.67$ for those $0-18$ years old. For children $0-5$ years old, the mean WHZ at baseline was $-0.42 \pm 1.49$. BMI z-score for children $5-18$ years old at baseline was $-0.44( \pm 1.34)$.

At baseline $788(34.1 \%)$ of children younger than 10 years of old were underweight and $1048(37.3 \%)$ of children ages $0-18$ years were stunted. Of those children younger than 5 years old, $212(12.6 \%)$ were wasted. Of children 5-18 years of age, $114(10.2 \%)$ were too thin/ 
Table 2 Total population mean anthropometric z-scores, malnutrition and anaemia prevalence at baseline

\section{Mean anthropometric baseline z-scores}

z-score ( $($ SD)

Weight-for-age $z$-score $(0-10$ years) $(n=2308)$

$-1.48 \pm 1.54$

Height-for-age $z$-score ( $0-18$ years) $(n=1686)$

$-1.74 \pm 1.67$

Weight-for-height $z$-score $(0-5$ years $)(n=1678)$

$-0.42 \pm 1.49$

BMI z-score ( $0-18$ years) $(n=2733)$

$-0.62 \pm 1.45$

Mid upper arm circumference-for-age $z$-score (6 months to 5 years) $(n=426)$

$-0.33 \pm 1.20$

Head circumference-for-age $z$-score $(0-5$ years) $(n=1095)$

Malnutrition prevalence

$-1.26 \pm 1.37$

Underweight (WAZ) (0-10 years) $(n=2308)$

Normal $(\geq 2)$

$\mathrm{n}(\%)$

Moderate ( $\geq 3$ to $\leq 2)$

$1520(65.9)$

Severe $(<-3)$

443 (19.2)

345 (15)

Stunting (HAZ) $(0-18$ years) $(\mathrm{n}=2812)$

$\begin{array}{lr}\text { Normal }(\geq 2) & 1764(62.7) \\ \text { Moderate }(\geq 3 \text { to } \leq 2) & 560(19.9) \\ \text { Severe }(\leq 3) & 488(17.4)\end{array}$

Wasted $(\mathrm{WHZ})(0-5$ years $)(\mathrm{n}=1678)$

Normal $(\geq 2)$

$1466(87.4)$

Moderate ( $\geq 3$ to $\leq 2)$

$137(8.2)$

Severe $(\leq 3)$

Overweight/thinness (BMIZ) (5-18 years) $(n=1123)$

Obese $(\geq 2)$

Overweight $(\geq 1$ to $<2)$

$118(10.5)$

Normal $(\geq 2$ to $<1)$

$874(77.8)$

Thinness $(\geq 3$ to $\leq 2)$

$80(7.1)$

Severe thinness $(\leq 3)$

34 (3)

Head circumference (HCAZ) (0-5 years) $(n=1095)$

$\begin{array}{lr}\text { Severe large }(\geq 3) & 7(0.6) \\ \text { Large }(\geq 2 \text { to }<3) & 10(0.9) \\ \text { Normal }(\geq 2 \text { to }<2) & 739(67.5) \\ \text { Small }(\geq 3 \text { to } \leq 2) & 214(19.5) \\ \text { Severe small }(\leq 3) & 125(11.4)\end{array}$

Anaemia $(0-18$ years $)(n=2494)$

Normal

$1777(71.3)$

Mild

$413(16.6)$

Moderate

$287(11.5)$

Severe

$17(0.7)$

ACAZ, mid-upper arm circumference-for-age z-score; BMI, body mass index; HAZ, height-for-age z-score; HCAZ, head circumference-forage z-score; WAZ, weight-for-age z-score; WHZ, weight-for-height z-score.

underweight. For children ages 5-18 years old, 135 (12\%) were overweight/obese. Of children ages $0-5$ years old, $339(31 \%)$ had a small head circumference.

Among those with disabilities who had anthropometric data available, at baseline $324(57.6 \%)$ of those under 10 years old were underweight and $368(56.3 \%)$ were stunted. Of children ages 5-18 years old, $38(16.2 \%)$ were too thin/underweight and $38(16.2 \%)$ were overweight/obese. For children with disabilities, $95(53.7 \%)$ had a small head circumference.

At baseline, of the total population 717 (28.8\%) had anaemia, with younger children more likely to have anaemia. Over time, anaemia severity and prevalence of anaemia reduced for most categories and age groups. Children younger than 5 years old and those younger than 5 years old 

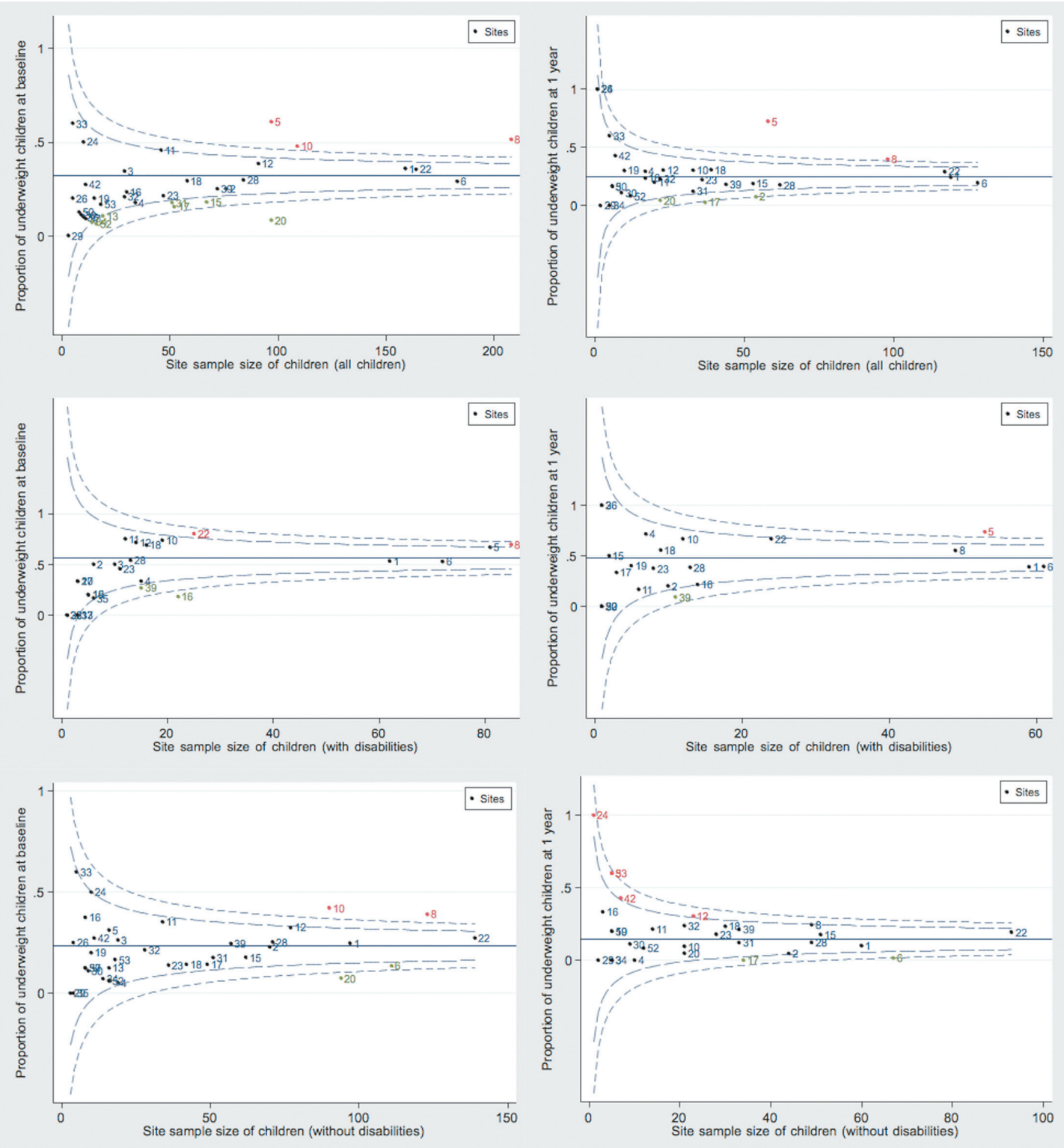

Figure 2 Funnel plots of the proportion of underweight children (WAZ), 0-10 years old at baseline screening (left side panels) and 1-year screening (right side panels). Top row includes all children, the middle row includes only those children with disabilities and the bottom row includes only those children without disabilities. Site identifiers above expected variation are in red, those within variation in black and those below expected variation in green. WAZ, weight-for-age z-score.

with a disability had similar anaemia prevalence; $461(34.4 \%)$ and $131(34.5 \%)$, respectively.

\section{Funnel plots}

Funnel plots (figure 2, online supplemental annex 2-6) show prevalence of anthropometric deficit in different sites over time and by disability status, identifying those sites which are outside of expected limits. Figure 2 shows weight-for-age prevalence. Sites 5 and 8 are outside the control limits with higher than expected prevalence of underweight children both baseline and 1year. At 1year, site 10 seems to have a higher proportion of underweight than would be expected compared with other sites. The mean prevalence of underweight is higher among children with disabilities than in those without. Online supplemental annex 2-6 show the same for other key anthropometric indicators-broad patterns are similar to underweight.

\section{SPC charts}

Figure 3 and online supplemental annex 7-10 show control charts for tracking site-level changes in anthropometric z-scores over time compared with total population UCL and LCL. Figure 3 shows mean WAZ change over time. Sites 1 and 6 illustrate sites with average (generally within the UCL and LCL) performance, respectively. Both sites have individual points outside of expected variation for children with disabilities, with a suggestion of a slight improvement in weight-for-age at 1 year for both sites, with site six maintaining the improvement over time. 

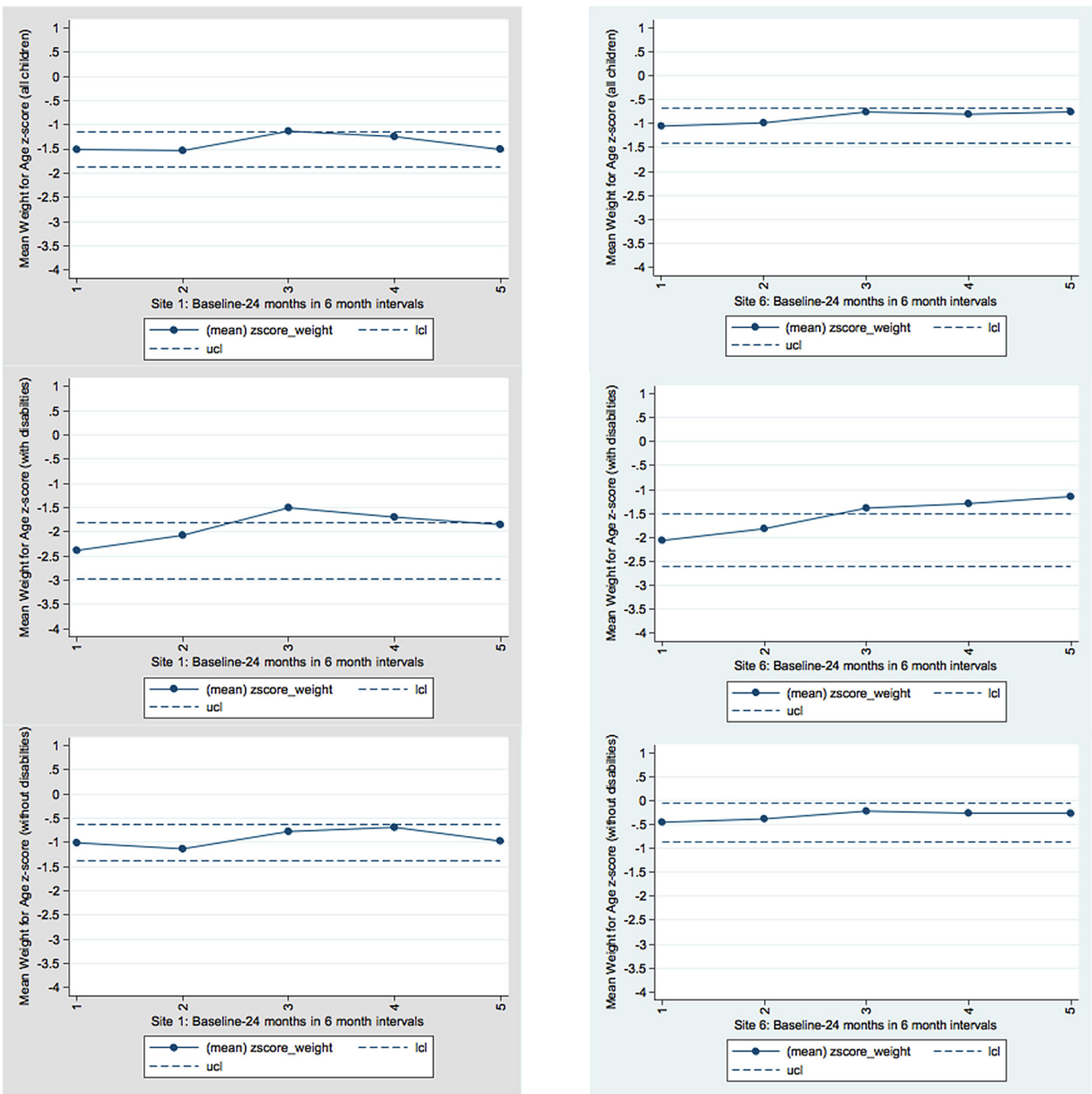

Figure 3 Individual site control charts showing the mean WAZ for children 0-10 years of age over time from baseline screening to 24-month screening. The top row includes all children; the middle row includes only those children with disabilities and bottom row includes only those children without disabilities. Upper control limits (UCL) and lower control limits (LCL) are indicated by the dashed lines; WAZ, weight-for-age z-score.

\section{DISCUSSION}

Our study presents comprehensive data on the nutritional status of children living within IBC and uses funnel plots and control charts to visualise intersite variations and progress over time in individual centres. Overall, children were at high risk of malnutrition, especially for those with disabilities.

Date of birth, birth weight, prematurity, age and length of stay There is a paucity of information on children's birth history and this requires healthcare professionals or site staff to estimate date of birth which can lead to inaccuracies for other indicators (eg, WAZ). Such data gaps can occur when children are abandoned without connections to birth family, when records are not forwarded from hospitals or other healthcare facilities or when unavailable. ${ }^{12}$ Aiming to receive available information is important and might be helped by improving transfer processes and by decreasing stigma for families placing children. Medical history matters because being born LBW or prematurely can increase children's risk of mortality, being stunted, wasted or developmentally delayed. ${ }^{4}$ For those with records available, we found a notably high prevalence of LBW, $514(57.5 \%)$ compared with the global prevalence of $14.6 \%$ and premature, $294(42.2 \%)$ vs the global prevalence of prematurity $10.6 \%$ (table 1 ). ${ }^{2627}$ The high proportion of young children and the median age of admission means that a large proportion of children are entering IBC early in life, within the developmentally sensitive 'first 1000 days' of life. ${ }^{4}$ The median length of stay indicates that children stay in care for around 2 years although some had lived within IBC for more than 13 years. This could indicate faster placement into families for young children or the challenge of finding homes for older children or those with the severest disabilities. This 
is important because the longer children stay within IBC, the more at risk they are for delayed development and malnutrition. ${ }^{1217}$

\section{Disability status}

Over a quarter of this population had one or more disabilities (table 1). This is markedly higher than the global prevalence of $5.1 \%$ of children younger than 15 years of age and for those older than 15 years of age $(14.9 \%) .^{28}$ Children with disabilities were significantly smaller than their peers without disability over multiple anthropometric indices and this continued over 2 years (table 2 and online supplemental annex table 11). Nutritional status of children with disabilities seems to improve for younger children over time but older children do not appear to improve, and in some cases worsen. It could be that children with more severe disabilities stay in IBC longer because of their high needs.

\section{Anaemia}

Almost a quarter of all children entered into the programme with anaemia, which was below the anaemia prevalence in low-income and middle income countries (LMICs) of $42.9 \%$ for children younger than 5 years old (table 2 and online supplemental annex table 11). ${ }^{5}$ Anaemia can impact brain development, cognition and growth. ${ }^{4}$ Children $0-6$ months had the highest prevalence of anaemia, which is expected with the high prevalence of LBW and premature births in the population. Throughout the 2-year period, the prevalence of anaemia reduced and moderate and severe anaemia eliminated for some age groups. This could be a reflection of access to health services or routine meals that children can experience in IBC, which may not be accessible to all community families. ${ }^{15} 29$

\section{Anthropometry}

Being underweight, wasted, stunted or thin can increase children's risk of infectious diseases, delayed development, mortality and non-communicable diseases. ${ }^{4}$ This can be especially serious for children with disabilities. ${ }^{410}$ We found for most anthropometric measurements, the total population of children have mean z-scores below the WHO mean for age (table 2, online supplemental annex table 11). ${ }^{22}$ Compared with the prevalence in LMIC there was a higher prevalence of malnutrition indicators, such as stunting, wasting and thin/underweight, with the one exception being overweight/obese children which was below global figures. ${ }^{5}$ Children with disabilities had more severe anthropometric deficits than their peers without disabilities and their prevalence of malnutrition overall was higher. The high prevalence of stunting for young children is especially concerning. For those younger than 5 years of age, $725(43 \%)$ and specifically those with a disability, $260(61.5 \%)$ were stunted. Catch-up from early-life stunting can be limited, especially for those outside of the developmentally sensitive 'first 1000 days'. Although children with some disabling conditions may be smaller or slighter than their peers without disabilities, stunting relevant to the normal growth potential of adequately nourished children with the same disabling conditions should not be overlooked. ${ }^{30}$ Wasting among children with disabilities was also higher than their peers without disabilities (without disability: $100(8 \%)$ vs children with disabilities: 112 (26.7\%) vs 2020 prevalence in LMIC: $6.8 \%) .{ }^{5}$ This could be related to a number of issues including difficulties swallowing/dysphagia, inadequate or poor nutrition, poor feeding practices, biological needs or caregiver practices or beliefs. ${ }^{10}{ }^{30}$ Children with disabilities who are wasted are at high risk of mortality and require specific care and inclusion in malnutrition treatment programmes. ${ }^{31}$ It is also notable that nearly a third of children younger than 5 years and over half of those with disabilities had a small head circumference, which although associated with preterm birth or some disabilities, could be an indicator of impacted brain development.

\section{Utility of control charts and funnel plots}

Funnel plots capture all of the sites at a specific time point, allowing easy visualisation of a particular indicator (eg, prevalence of underweight children) and comparing sites with each other to highlight those inside versus outside of control limits. In the control charts, we see individual sites trends over time in comparison to the site's limits. Using these charts is an easy way of distinguishing normal inter-site variations from statistically significant variations which warrant site visits and in-depth consultations to explore possible reasons and potential extra need for support (figures 2 and 3, online supplemental annex 2-10).

Together these charts could help healthcare providers better track and monitor the nutritional needs of their individual sites with tools that provide expected limits and take into account the existence of natural variation. These charts will be added to Holt International's nutrition screening database to allow programme staff to evaluate the impact of programmes in a way that is easily understandable, interpretable and provides up-to-date information. These automated charts in tandem with tools and training provided by Holt's Child Nutrition Programme, will support sites to appropriately conduct targeted nutrition interventions when needed.

\section{Limitations}

There were several limitations in our study. First, though our sample was large both in terms of individual children and different centres across several countries, those may not be representative of all similar institutions within all of the countries. As a large global non-governmental organisation, Holt International offers support and resources that many locally-funded centres may not have and the nutritional status of the wider group of children in IBC is likely to be worse than our data suggest. The uniqueness of the children who come into IBC and the environments in IBC are also likely not reflective of wider local 
community populations. This is concerning since children arrive malnourished and high quality (and costly) nutrition and care is needed to optimise their chances of catch-up growth.

Other limitations included unknown prior history, stage of entry into care and length of stay in the programmeall of which could impact growth. For some, their first screening was their first day into IBC but for others, it occurred multiple years into living in IBC. Changes over time may be more impactful for different children depending on how long they are in IBC prior to their first screening. Potential biases include measurement error which could have occurred during anthropometric assessment as measurements can be especially difficult for children with disabilities. ${ }^{30}$ Disabilities also, though diagnosed by qualified health professionals in all countries were not assessed by a standardised method, such as the 'Washington Group' questionnaire, which would enable a more comparative analysis. ${ }^{31}{ }^{32}$ Future analysis should include additional categorisation of many other disabilities, including physical disabilities. Although grouping those with and without disabilities does help understand intercentre variations, this simple split does not address the individual needs of children. Children with some types of disabilities may be small or underweight for age based on clinical sequelae related to their specific disability. These disabilities may impede their ability to feed themselves, digest food or be associated with conditions that would reflect in lower height or weight. Another limitation was a decrease in sample sizes over time and some small site sample sizes. This decrease may introduce biases as some children exit the programme, such as those who are healthier being placed into family-based care at a higher rate and those needing more support staying in care longer.

\section{CONCLUSION}

Malnourished children in IBC are at risk of not fulfilling their growth potential and are thus more vulnerable to serious illness, becoming disabled or exacerbating existing disabilities. We found a high prevalence of children who are malnourished or at risk for malnutrition. Many were born LBW, prematurely or have an underlying disability. Those with disabilities were found to have a higher prevalence of malnutrition than children without disabilities. Control charts could be a valuable tool to track and monitor children's growth and inter-centre variations. Future research should aim to understand the reasons for intercentre variations in more detail and also formally explore the utility of control charts over more standard methods of presenting key data. The nutritional needs of close to 10 million children in IBC around the world are likely high and worthy of greater global attention. Children have a basic human right to grow and fully develop regardless of where they received care early in their lives.

\section{Author affiliations}

${ }^{1}$ Department of Epidemiology \& Population Health, London School of Hygiene \& Tropical Medicine, London, UK

${ }^{2}$ Nutrition \& Health Department, Holt International, Eugene, Oregon, USA

${ }^{3}$ Centre for Maternal Adolescent Reproductive and Child Health, London School of Hygiene and Tropical Medicine, London, UK

${ }^{4}$ Department of Infectious Disease Epidemiology, London School of Hygiene and Tropical Medicine, London, UK

${ }^{5}$ Neonatal Medicine, University College London Hospitals NHS Foundation Trust, London, UK

${ }^{6}$ International Disability Research Centre, University College London, London, UK ${ }^{7}$ Holt Haiti Country Office, Holt International, Port-au-Prince, Haiti

${ }^{8}$ Department of Health Sciences, Central Washington University, Ellensburg, Washington, USA

${ }^{9}$ Nutrition Department, Kaisahang Buhay Foundation, Inc, Quezon City, Philippines

Correction notice This article has been corrected since it first published. Supplementary files are updated.

\section{Acknowledgements Chris Doig, Ali Murray.}

Contributors ED, MK, EA and CJT designed the study. ED, MK, EH, MQ, CJT, NEG, EA, MD-A, HTD, JV and EB contributed to specific areas of the methods, data analysis, statistics and quality control. ED, MK, MQ and EH had access and verified the data. ED led the data analysis and writing of the first draft of the manuscript. $E D, M K, E H, M Q, C J T, E A, N E G, M D-A, H T D, J V$ and EB contributed to the writing of the manuscript and agree with the manuscript's results and conclusions. All of the authors read and approve of the submitted manuscript. ED is the guarantor of this study.

Funding The authors have not declared a specific grant for this research from any funding agency in the public, commercial or not-for-profit sectors.

\section{Competing interests None declared.}

Patient consent for publication Not applicable.

Ethics approval Ethical approval was obtained from the London School of Hygiene and Tropical Medicine's Ethics Committee (ref: 17808).

Provenance and peer review Not commissioned; externally peer reviewed.

Data availability statement Data may be obtained from a third party and are not publicly available. Data may be obtained from a third party and are not publicly available. Relevant research and data information has been stored in the London School of Hygiene and Tropical Medicine's Data Compass. DeLacey, E (2020). Data for: 'The nutritional status of children living within institutionalised care: a retrospective analysis with control charts for program monitoring'. (Data Collection). London School of Hygiene and Tropical Medicine, London, UK. https:// doi.org/10.17037/DATA.00001994. Requests for access to this data need to be directed to Holt International. The data will be shared only on a contingent approval basis with interested parties. Additional related study protocols can be requested. Approval of a proposal, a data management protocol and a signed data access agreement will be required. To be addressed by: Holt International, info@holtinternational.org; 250 Country Club Road, Eugene, OR 97401; tel: 541.687 .2202

Supplemental material This content has been supplied by the author(s). It has not been vetted by BMJ Publishing Group Limited (BMJ) and may not have been peer-reviewed. Any opinions or recommendations discussed are solely those of the author(s) and are not endorsed by BMJ. BMJ disclaims all liability and responsibility arising from any reliance placed on the content. Where the content includes any translated material, BMJ does not warrant the accuracy and reliability of the translations (including but not limited to local regulations, clinical guidelines, terminology, drug names and drug dosages), and is not responsible for any error and/or omissions arising from translation and adaptation or otherwise.

Open access This is an open access article distributed in accordance with the Creative Commons Attribution Non Commercial (CC BY-NC 4.0) license, which permits others to distribute, remix, adapt, build upon this work non-commercially, and license their derivative works on different terms, provided the original work is properly cited, appropriate credit is given, any changes made indicated, and the use is non-commercial. See: http://creativecommons.org/licenses/by-nc/4.0/.

\section{ORCID iDs}

Emily DeLacey http://orcid.org/0000-0003-2286-6430

Marko Kerac http://orcid.org/0000-0002-3745-7317 


\section{REFERENCES}

1 UNICEF. Orphans, 2017. Available: https://www.unicef.org/media/ media 45279.htm

2 United Nations General Assembly. Guidelines for the alternative care of children, un document A/RES/64/142. Geneva: United Nations, 2009.

3 Desmond C, Watt K, Saha A, et al. Prevalence and number of children living in institutional care: global, regional, and country estimates. Lancet Child Adolesc Health 2020;4:370-7.

4 Black RE, Victora CG, Walker SP, et al. Maternal and child undernutrition and overweight in low-income and middle-income countries. Lancet 2013;382:427-51.

5 The World Bank Group. DataBank: health nutrition and population statistics, 2019. Available: http://datatopics.worldbank.org/health/

6 UNICEF. Malnutrition, 2019. Available: https://data.unicef.org/topic/ nutrition/malnutrition/

7 Headey D, Heidkamp R, Osendarp S, et al. Impacts of COVID-19 on childhood malnutrition and nutrition-related mortality. The Lancet 2020;396:519-21.

8 Goldman PS, van ljzendoorn MH, Sonuga-Barke EJS, et al. The implications of COVID-19 for the care of children living in residential institutions. Lancet Child Adolesc Health 2020;4:e12.

9 DeLacey E, Tann C, Groce N, et al. The nutritional status of children living within institutionalized care: a systematic review. PeerJ 2020;8:e8484.

10 Groce N, Challenger E, Berman-Bieler R, et al. Malnutrition and disability: unexplored opportunities for collaboration. Paediatr Int Child Health 2014;34:308-14.

11 The causes of children's institutionalization in Romania. The children's health care collaborative Study Group. Child Care Health Dev 1994;20:77-88.

12 The St. Petersburg- USA Orphanage Research Team. Characteristics of children, caregivers, and orphanages for young children in St. Petersburg, Russian Federation. J Appl Dev Psychol 2005;26:477-506.

13 The St. Petersburg- USA Orphanage Research Team. The effects of early social-emotional and relationship experience on the development of young orphanage children. Monogr Soc Res Child Dev 2008;73:1-270.

14 Baron AM, Baron YM, Spencer NJ. The care and health needs of children in residential care in the Maltese Islands. Child Care Health Dev 2001;27:251-62.

15 Whetten K, Ostermann J, Pence BW, et al. Three-Year change in the wellbeing of orphaned and separated children in institutional and family-based care settings in five low- and middle-income countries. PLoS One 2014:9:e104872.

16 Frank DA, Klass PE, Earls F, et al. Infants and young children in orphanages: one view from pediatrics and child psychiatry. Pediatrics 1996;97:569-78.

17 Johnson DE, Gunnar MR. Iv. growth failure in institutionalized children. Monogr Soc Res Child Dev 2011;76:92-126.

18 van IJzendoorn MH, Palacios J, Sonuga-Barke EJS, et al. Children in institutional care: delayed development and resilience. Monogr Soc Res Child Dev 2011;76:8-30.

19 von Elm E, Altman DG, Egger M, et al. The strengthening the reporting of observational studies in epidemiology (STROBE) statement: guidelines for reporting observational studies. Lancet 2007;370:1453-7.

20 Stata Statistical Software: Release 16 [program]. College Station, TX: StataCorp LLC 2019.

21 World Health Organization. Who hemoglobin concentrations for the diagnosis of anemia and assessment of severity. Geneva: Vitamin and Mineral Nutrition Information System, 2011.

22 World Health Organization. The who child growth standards, 2019. Available: https://www.who.int/childgrowth/standards/en/

23 World Health Organization. Growth reference data for 5-19 years, 2019. Available: https://www.who.int/growthref/en/

24 Benneyan. Statistical process control as a tool for research and healthcare improvement, 2003.

25 Benneyan JC. Use and interpretation of statistical quality control charts. Int J Qual Health Care 1998;10:69-73.

26 Blencowe $\mathrm{H}$, Krasevec J, de Onis M, et al. National, regional, and worldwide estimates of low birthweight in 2015, with trends from 2000: a systematic analysis. Lancet Glob Health 2019;7:e849-60.

27 Chawanpaiboon S, Vogel JP, Moller A-B, et al. Global, regional, and national estimates of levels of preterm birth in 2014: a systematic review and modelling analysis. Lancet Glob Health 2019;7:e37-46.

28 World Health Organization. World report on disability. Geneva: Switzerland, 2011.

29 Panpanich R, Brabin B, Gonani A, et al. Are orphans at increased risk of malnutrition in Malawi? Ann Trop Paediatr 1999;19:279-85.

30 Groce NE, Kerac M, Farkas A, et al. Inclusive nutrition for children and adults with disabilities. Lancet Glob Health 2013;1:e180-1.

31 Lelijveld N, Groce N, Patel S, et al. Long-Term outcomes for children with disability and severe acute malnutrition in Malawi. BMJ Glob Health 2020;5:e002613.

32 Washington group on disability statistics. Washington group on disability statistics, 2020. Available: https://www.washingtongroupdisability.com/2001 [Accessed 21 Nov 2020]. 